\title{
Ciência na nossa cultura? Uma práxis de educação em ciências e matemática: oficinas participativas
}

\author{
Maurice Bazin*
}

Foi-me solicitado um artigo "com a intenção de divulgar as idéias da cultura científica e tecnológica" como "atividade preparatória ao $3^{\circ} \mathrm{Sim}$ pósio do ICASE". Esta colocação me leva a tentar esclarecer o que seria aquela "cultura científica e tecnológica" e porque seria necessário divulgar suas idéias. Enquanto, você, leitor, me lê como "atividade preparatória" ao Simpósio, eu ando procurando fitas de papel, garrafas de plástico transparente, bexigas, pilhas usadas, plaquinhas de cobre, outras de zinco ou alumínio, conta-gotas, e flechas originais dos índios Kaingang. Com aquele material "tecnológico", e sem palestrar, oferecerei durante a nossa reunião algumas oficinas: acompanharei um grupo de duas dúzias de colegas-professores em seus esforços de fazer Ciência e matemática, envolvendo-se comigo em questionar o mundo material e técnico que nos rodeia, e de elucidar os conceitos matemáticos e físicos que nossas manipulações revelarão. Essas atividades terão como meta poder levar as crianças a viverem na sala de aula sessões de descobrimento e discussão tão ricas, surpreendentes e agradáveis como as que viveremos juntos entre docentes. Assim, possivelmente, ofereceremos alguma coisa de Ciência à nossa cultura.

* Ph. D, Universidade Federal de Santa Catarina, Brasil.

E-mail: mauriceb@exploratorium.edu 


\section{Ciência e Cultura}

A palavra cultura é muito carregada de valor, de emoções, de seguranças para alguns e, portanto, de inseguranças para outros. Será a cultura de um grupo humano uma "civilização"? Quem é civilizado? Historicamente, quem civilizou quem, a partir da "civilidade" das cidades? Admiração dos europeus quando encontraram Timbuctu! Surpresa do cientista viajante francês, La Condamine, quando viu os índios da Amazônia tratarem a seiva de uma árvore para fazer "cautchu", técnica apropriada hoje por Michelin e Firestone. Mas os americanos do Norte insistem em utilizar a noção de cultural lag (atraso cultural) em seus dicionários para estudantes universitários. O definem como "atraso notável na taxa de desenvolvimento de certos aspectos duma cultura em comparação com outras". Pensem nas culturas "atrasadas" que os "descobridores" encontraram, sem aceitar as contribuições que elas estão ainda trazendo para as companhias farmacêuticas transnacionais. Para eles, então, cultura é algo dinâmico, com "taxa de desenvolvimento", como a produção industrial. Na civilização ocidental há hierarquia entre culturas. Segurança dos colonizadores; insegurança levando à dependência dos colonizados. Oh! velho imperialismo cultural.... Oh! reino dos privilegiados dos países dependentes que adotaram a cultura "dominante". Quem ficou confortavelmente preso naquela rede de privilégios elaborados fora foram os próprios cientistas. Eles aproveitaram bem a ascendência da Ciência e da Tecnologia e criaram institutos, centros e laboratórios dos quais saem somente para centros, laboratórios e institutos no exterior. $\mathrm{O}$ que pode exibir cultura própria não é a ciência, são pessoas, no nosso caso de interesse os cientistas que trabalham na ciência.

Os americanos do Norte vêem ciência e cultura como entidades totalmente separadas: consideram que a Ciência avança mais rapidamente do que a própria sociedade civil, que fica atrás. Nesta ótica, a responsabilidade dos educadores e divulgadores da Ciência seria imediatista e deveria consistir em apresentar e explicar os últimos assuntos em moda. Mas, olhando com um pouco de modéstia, a gente pode ver que as próprias modas recentes consistem em reabrir tópicos abertos muitos anos atrás e deixados inacabados: a última a chegar, a "complexidade", subindo um grau meramente lingüístico acima do "caos" que a precedeu, retoma preocupações matemáticas do início do século na mecânica de sistemas dinâmicos (por exemplo a nossa atmosfera, na qual pequenos acon- 
tecimentos podem ter efeitos enormes num outro lugar mais tarde: "uma borboleta bate asas no Brasil e acontece um tornado no Texas" [Lorenz, 1972].) O que falta é a cultura da memória da ciência entre os próprios cientistas. No caso citado foi a falta não só do reconhecimento do valor das obras do passado (porque muitas comissões pedagógicas oficiais tanto na França como nos Estados Unidos apontaram este valor) mas de manter na prática o uso destas obras. Certamente o que Galileu observou na lua com a sua luneta todos poderíamos observar hoje, especialmente porque no domínio da astronomia existem "amadores" prontos a cultivar e reculturar estas observações conosco. O que Oersted observou 200 anos atrás colocando uma agulha de marear perto de um fio metálico percorrido por uma corrente elétrica vinda do empilhamento alternado de pedaços de dois metais separados por pedaços de couro úmido inventado por Volta, podemos construir e fazer em qualquer escola do país. É certo que a dificuldade profunda em colocar uma prática de Ciência no ensino de cada dia é o fato de todos nós, professores, termos tido uma formação secundária ("muito secundária mesmo!"' segundo um poeta do Québec) toda teórico-irrealista, sem tocar no real com os dedos, nem olhar com os olhos. Aos Secretários de Educação que colocam como prioridade orçamentária a compra de computadores para as escolas "entrarem no século XX ou XXI" dependendo das regiões do país, gostaria de apontar que nem Galileu, nem Oersted, nem Faraday precisaram de computador e que o país seria cientificamente culto se todos os professores soubessem fazer, apreciar e elaborar aquelas experiências e raciocínios que Galileu, Oersted e Faraday viveram. Imaginem um país no qual todas as pessoas, hoje, soubessem tudo o que Galileu sabia e as imaginem conversando com seus filhos como Galileu conversava com seu ajudante. Naquele país, então, os professores poderiam proveitosamente discutir a melhor maneira de acompanhar todos os estudantes para fazerem aquelas experiências e raciocínios numa sala da escola ou fora dela; certamente não numa sala de "aula" teórica! Poderiam definir uma práxis. E então a bagagem histórica da ciência se incorporaria à cultura. Estamos muito longe de tal situação. É abuso de linguagem falar de "cultura tecnológica" ao descrever a mera presença de computadores nas escolas. É também pretender não saber que corresponde à insistência dos fabricantes de artigos tecnológicos em criar um novo mercado, numa versão modernizada da comercialização forçada de retroprojetores e projetores de slides 30 anos atrás.

O que seria essa "cultura científica e tecnológica"? Falar em cultura implica a existência de pessoas que a vivem. Mas não se trata aqui de estudar a maneira "cultural" de ser dos cientistas e técnicos para definir uma 
cultura específica deles. Individualmente, eles fazem parte da sociedade e de sua cultura: eles tradicionalmente almoçam com os pais aos domingos. A questão mais interessante é saber se o que eles fazem, Ciência ou Tecnologia, tem entrado na cultura das outras pessoas da cidade, da região ou do país. Não é uma questão de notar a presença de objetos tecnológicos na sociedade. A questão é saber se as pessoas se apropriaram dos conteúdos da ciência e se apreciaram os mecanismos interiores dos objetos tecnológicos. Me parece que isto não aconteceu, nem aqui, nem nos países ditos desenvolvidos. Uma sociedade ser tecnologificada não significa que as tecnologias entraram na cultura do povo daquela sociedade. Não é porque bancos e lojas de companhias de aviação viraram balcões de computadores que as pessoas entendem o seu funcionamento como entendiam o funcionamento das máquinas de escrever mecânicas. Os instrumentos tecnológicos comuns ficam mais e mais impenetráveis. Eles fazem parte do nosso dia-a-dia sem fazer parte do nosso conhecimento. A última meta dos vendedores de computadores é fazê-los tão user-friendly que não seja preciso saber nada sobre como funcionam. Este fenômeno vai contra a entrada de conhecimentos tecnológicos na cultura geral: o desenhista desenha facilmente, o escritor escreve facilmente. Ninguém tem contato com a ciência que está por trás do instrumento que usa; o instrumento continua como uma caixa preta, mas sorridente.

O problema social da Ciência é justamente não estar NA cultura. A população em geral não domina ou mesmo entende as coisas de ciência e as criações tecnológicas, e não tem chance de descobrir se gosta. Democracia deixa a Ciência fora de seu funcionamento. Hoje o povo não participa da criação da Ciência, Ciência é atividade de uma elite. Aquela elite imita no seu comportamento os colegas do Norte, norteia-se por eles e nunca imaginaria sulear-se pelas idéias culturais das civilizações andinas. Nem consegue assumir-se a si própria como pensando na ciência em língua portuguesa: no início dos anos 90, a SBPC decidiu transformar sua revista "Ciência e Cultura" numa revista totalmente escrita em inglês! Ficou o título em português... Isto eliminou muitos leitores brasileiros e não fez com que a publicação fosse reconhecida como revista "internacional" de alto nível: não ficou listada no International Index de referências. A ciência tampouco penetrou a cultura "popular", ao contrário de outros interesses humanos como a música ou o esporte, ou mesmo a religião, que nunca estiveram fora da cultura, mas se elaboram no próprio ser cultural.

O teste desta ausência não reside na distorcida avaliação de conhecimentos que aparece repetidamente nos jornais de todos os países, "revelando" que $30 \%$ ou $50 \%$ (ou qualquer número entre 20 e 80 ) dos en- 
trevistados acreditam que "o Sol gira ao redor da Terra". Mesmo a decisão de fazer aquela pergunta sem contexto nenhum revela o quanto os próprios jornalistas se confundem e mistificam os assuntos quando pretendem tratar de ciência. Aquela pergunta estreitinha não tem a ver com um conhecimento ou uma prática científica: na minha prática observacional vejo o Sol girar ao nosso redor a cada dia, sim. Demora um ano inteiro para a Terra girar ao redor do Sol! De um outro ponto de observação, todo dia também, ela gira sobre si própria. Aprofundar esta conversa não se cogita na cultura jornalística: essa, como prática profissional, não cultiva a ciência.

Os próprios cientistas muitas vezes não fazem um trabalho de apresentação menos mistificador do que os jornalistas. Muitos ainda gostam de ser fotografados vestindo o uniforme do professor Pardal. A bata branca mantém distância (vertical, of course) entre o perito e "seu" público. Eu a vi recentemente no noticiário da Globo vestindo um professor sentado ao lado dum aparelho para detectar problemas nas formas dos pés de crianças: a criança pisa num tabuleiro e aparecem manchas coloridas ao redor dos pontos de apoio dos pés na tela de um computador. Assim, dizia o professor, detectam-se "más posturas" e "pés chatos". Além de poder dizer que usa as "últimas tecnologias", nosso professor pretende participar de melhorias na ortopedia. Acontece que a presença de crianças com estruturas ósseas fracas ou deformadas não é bem um problema técnico de detecção; é um problema de nutrição. Não é um problema científico, mas um problema social. O professor está cientificamente preocupado com seu novo gadget por si, num departamento universitário que oferece teses de pesquisa em biologia. Não estuda ou propaga noções de alimentação sadia. Aquela preocupação pertence a outro quadro da TV Globo, mostrando os efeitos da seca no Nordeste e avivando a saudade cultural do Betinho (aquele sociólogo, lembra?) O Betinho tentou recolocar a solidariedade na nossa cultura de maneira prática. Quem poderá colocar lá a Ciência?

Parece que possuir cultura técnica é ter abundância de gadgets, imitando o aspecto "pesquisa e desenvolvimento" "de ponta" dos países ditos desenvolvidos. Entretanto, aqui mostram-nos algumas gadgets-maquinetinhas socialmente absurdas. O físico que escreve estas linhas conheceu na infância o racionamento do leite (um quarto de litro por semana, por criança, na cidade de Paris, durante a ocupação alemã) e sabe nos ossos que pés chatos resultam da má nutrição infantil.

Virando a página, onde devo procurar a "cultura científica e tecnológica" nos jornais? Não na seção "Cultura"! Ciência e Tecnologia têm sua seção própria, fora da "cultura". Poderia ser menos cientificamente 
radical nesta demonstração e reconhecer que a presença de uma seção de CT nos jornais e de uma rubrica correspondente nos noticiários de TV representa uma certa entrada das coisas de Ciência no cotidiano das pessoas. Mas aqueles artigos sobre Ciência são meras notícias de algo "novo" ou sensacional, algo tanto mais atraente quanto mais perto estiver de figurar num Guiness Book do progresso!

Naquela seção de jornal escrevem jornalistas científicos. Nas outras seções, na de cultura em particular, encontramos artigos escritos por críticos literários, críticos de teatro, críticos de música, oferecendo opiniões e recomendações. Não existem críticos de ciência. A ciência não está aberta para a crítica de fora; ninguém se permite olhar os seus produtos, menos ainda a sua elaboração, como se olha um quadro. Ninguém diz: "não gosto, porque é confuso" ou "gosto, porque me faz pensar na minha relação com a natureza". Desta maneira, a ciência não está de nenhum jeito como objeto da nossa cultura crítica.

Existe uma cultura esportiva; por conseguinte, há uma crítica esportiva, torcidas, vaias; muita gente envolvida, sabendo as regras e as dificuldades por trás de cada jogada; muita gente com experiência própria que, portanto, está apreciando, tomando gosto, saboreando, julgando. Mas, e a Ciência, quem imagina apreciá-la desta maneira? Os cientistas não trabalham em campo aberto. O jardineiro do professor ortopédico joga futebol e comenta a partida entre os amigos. Mas ele nunca poderá "apreciar" como aparecem as cores ao redor dos pontos de apoio dos pés no tabuleiro ligado ao computador. Ele nunca teve experiência própria em ciência: na escola, bebeu palavras e repetiu definições.

Há uma cultura musical e uma crítica da produção musical: novos CD's; "gostei, não gostei". "Os acordes distoam...." Todo mundo sabe o que é um acorde. $\mathrm{O}$ gosto pode mudar, mas existe gosto. A população participa da vida musical e se expressa criticamente em todo lugar. Ninguém se pergunta se a música está NA cultura, popular ou geral... Aqui no Brasil não há dúvida de que a música faz parte da cultura e até da civilização brasileira. Os músicos que a praticam pertencem a todos os níveis da sociedade. A empregada do professor canta Tom Jobim e Vinicius de Moraes e escolhe ao som de que orquestra vai dançar no fim de semana. Ela canta e seu filho toca violão. O povo brasileiro está alfabetizado em música. Nada e ninguém o alfabetizam em ciência.

Para os europeus e para os brasileiros que contemplam a Europa, cultura é coisa séria, que está lá há muito tempo, uma maneira de viver e pensar transmitida de geração em geração. Um político francês da 
primeira metade do século XX falava que "cultura é o que fica quando se tem esquecido de tudo".

Epistemologicamente, a atividade científica não tem cultura, no sentido europeu, porque não tem memória. Em ciência, o último nascido é sempre o melhor: a maioria das referências ou citações nas revistas de pesquisa abrangem os últimos dois anos. $\mathrm{O}$ passado fica varrido, os peritos de hoje não lêem os peritos de anteontem; para quem está ao lado, tudo muda sem deixar húmus no qual enraizar uma apreciação. Villa-Lobos não eliminou Beethoven! A Bossa Nova não eliminou as cantigas de roda. As obras humanas são apresentadas na seção "cultura" dos periódicos fícam: um poeta não faz esquecer um poeta; um músico não faz esquecer um músico. Com o tempo, a arte se acumula, mas a ciência substitui: Einstein supostamente eliminou Newton, que eliminou Galileu, que eliminou a Igreja.

\section{Ciência e Educação}

Intrinsecamente, a maneira de evoluir da Ciência elimina a possibilidade do aproveitamento pedagógico da sua construção passo a passo. Ao avançar, ao criar o seu progresso, ela esquece, passa por cima das criações anteriores e as supera! Ela somente sabe superar, ultrapassar! Daí a ideologia mecanicista e reducionista de progresso-trem bala... Assim, pretendese eliminar o princípio pelo qual o que uma criança aprende enquanto cresce deve passar naturalmente pelas mesmas etapas que a Humanidade como um todo percorreu historicamente para elaborar os seus conhecimentos. Esta visão pedagógica é um caso particular de um princípio geral conhecido pelo nome-título do primeiro livro de Stephen Jay Gould, "Ontogeny and Phylogeny". Ele aponta o paralelismo entre o crescimento biológico individual desde um embrião até um ser adulto e a formação e desenvolvimento da nossa espécie que saiu da bolsa amniótica marítima e evoluiu no tempo até nossa espécie.

O ensino de Ciências deixa de lado este princípio e ignora sua história. A apresentação mediática dos assuntos científicos e tecnológicos pretende nos levar às fronteiras de buracos negros sem nos fazer passar pela experiência da variação de aceleração numa montanha russa ou experimentar os planos inclinados de Galileu. 
Uma das razões porque a educação habitual em Ciência e a sua divulgação mediática não dão resultados é que a Ciência não consiste numa série de resultados a serem enumerados. Ela é uma atividade viva, engajada e sempre renovada. Não pode ser assimilada através de uma mera escuta passiva. Precisa ser praticada de verdade. Não servem as sessões de laboratório para "verificar" o que se escutou nas "aulas teóricas". O engano está de fato reconhecido pela própria maneira de dar notas aos alunos. Chegado o fim do curso, o trabalho laboratorial vale somente por alguns pontos, em comparação com as dezenas de pontos atribuídos aos trabalhos "teóricos" escritos.

Mas, apesar de todas as razões que fazem a Ciência ficar fora da cultura; apesar do respeito acrítico por parte do resto da sociedade que os cientistas utilizam para manter seus privilégios, apesar de seu próprio Ministério em Brasília ficar bem longe do Ministério da Cultura (quando existe!) e apesar do ruído superficial dos clips tecnológicos da mídia, algumas pessoas insistem em tomar a sério a meta de remediar o analfabetismo técnico-científico generalizado na nossa sociedade. Na obstinação que elas demonstram, sobrevivem as práxis de Paulo Freire e do fundador do Exploratorium, Frank Oppenheimer.

\section{Práxis na educação em ciências e matemática: oficinas participativas}

"Faça você mesmo", pedia a faixa do Espaço Ciência Viva, esticada atrás de uma mesa coberta com microscópios numa praça pública do Rio de Janeiro nos anos 80. E ainda hoje os educadores práticos do Espaço Ciência Viva, no Rio de Janeiro, continuam oferecendo atividades concretas para escolares fazerem em seu galpão da Tijuca.

"Esta oficina é um exemplo de uma pedagogia no ensino de ciências que facilita a aprendizagem através do diálogo e da descoberta. O método é tão velho quanto Sócrates, e também Paulo Freire. É um método que os pesquisadores acadêmicos discutem e rediscutem, mas que muito poucos têm a coragem e modéstia de praticar. O ensino típico da Ciência permanece dominado pela palestração, às vezes acompanhada por alguma demonstração teatral: sempre um perito que "alimenta" sua platéia.

Nossa metodologia é diferente; envolve ensinar com respeito, permitindo a 
aprendizagem no ritmo dos aprendizes, em interação com eles. Aprende-se construindo a realidade concreta do mundo natural que está sendo investigado, desvelado, re-descoberto pelo grupo, criando e apreciando o próprio processo. Representa a filosofia de ensino do Instituto do Professor do Exploratorium.

Esta é a introdução de um documento vídeo que Andrej Zdravic filmou nos anos 90 no Teacher Institute do Exploratorium em San Francisco, California, uma atividade-oficina com professores sobre a difração da luz, que coordenei.

Existe hoje no Brasil a revista Ciência Hoje das Crianças, que todo mês tenta atingir os professores das escolas públicas com exemplos de atividades concretas para as crianças viverem o fazer da ciência e descobrirem conceitos básicos. Mesmo o MEC tendo diminuído seu apoio financeiro e cortado sua contribuição à distribuição da revista pela metade (ao aproximar-se um período eleitoral....), as pessoas que a produzem insistem em manter o conteúdo fiel a uma pedagogia respeitosa, ao aproveitamento da história dos trabalhos científicos, à verdade de como nasce a ciência e como pode ser feita e apreciada concretamente por cada um.

Após os anos 60 na Europa e nos Estados Unidos, e desde o fim dos anos militares no Brasil, uma certa "abertura" na prática pedagógica popular tem aparecido, quase sempre fora do mundo oficial e conseqüentemente apresentada pelos meios de comunicação globais como "experiências" ou "projetos" limitados, que não ameaçam os interesses de dominação geral dos poderes vigentes.

Todas essas atividades têm em comum a meta de participação dos aprendizes como sujeitos. No caso específico de "fazer ciência" como atividade de conscientização, a prática precisa elaborar seus próprios "temas geradores" ou, mais realisticamente, seus "equipamentos geradores" tecnológicos que permitam desvelar os princípios científicos que sustentam o seu funcionamento. Quando pensamos em ajudar professores a retomar o nível original de alfabetização científica, nossos objetos concretos de partida são escolhidos para nos permitir desvelar, analisar e apreciar com prazer alguns fenômenos que geram nossa maneira "científica" de entender o mundo físico que nos rodeia. Desenvolvemos aquilo em conjunto, num círculo de trabalho manual e de discussão, filho do "círculo de cultura" dos alfabetizadores freirianos. Esta maneira de trabalhar chamamos de "oficina de descobrimentos participativos", e não é somente de descobrimentos, mas também de interpretação, de procura de palavras certas, de apreciação das palavras consagradas, da revelação informal de todas as 
imagens, as referências e as ligações que essas palavras trazem às nossas cabeças.

Em termos sociais, este estilo de trabalho é libertador; ele certamente não participa da manutenção de mitos sobre o que é ciência ou fazer ciência; ele não utiliza métodos dominadores com bata branca toda sabedora. Mas, se ele não se dirigir em prioridade aos professores do ensino público com vista a ser utilizado para libertar por sua vez os piás do povo, nosso trabalho ficará como mero exercício entre privilegiados nacionais.

Este estilo de trabalho não se presta a descrições e modificações curriculares infinitas como as que alimentam a estagnação pedagógica oficial. Serve muito bem para satisfazer qualquer currículo-lista-de-temas publicado para os professores seguirem. Consiste, por exemplo, em vez de escrever no quadro as leis da flutuação, em levar grupos de três estudantes para experimentar com garrafas plásticas, água e conta-gotas ou pacotinhos de catchup, tendo tanto prazer em fazer e discutir "submarinos de garrafa" como teve o senhor Descartes (que brincava assim com seus amigos e, principalmente, amigas). E, como ele, chegar a sistematizar as observações, reconhecer o fenômeno mais geral e procurar novos materiais para pesquisá-lo mais ainda.

A reentrada da ciência e das tecnologias na cultura geral não consiste num exercício de imaginação. Ela visa des-truir a recente e cientificamente desenvolvida cultura de exploração à qual são submetidas enormes quantidades de pessoas de todas as cores, mas principalmente mulheres, nas fábricas das indústrias tecnológicas high-tech. Sediadas financeiramente no Liechtenstein ou nas Bahamas (onde os impostos são doces), produzem de verdade nos lugares por elas transformados em zonas "francas" (francas para elas, visto que assim escapam ao controle das leis de Estados constituídos e não precisam seguir regras de proteção nem dos trabalhadores nem da natureza). Com o conveniente desenvolvimento das redes de transporte e de comunicação, estas companhias organizaram suas linhas de produção pelo mundo inteiro, orquestrando suas unidades de produção off-shore de Singapura a Manaus. Assim uma verdadeira subcultura de exploração humana cientificamente organizada subentende a pretendida "cultura científica e tecnológica", possivelmente facilitada no caso do Brasil pela cultura escravagista, abolida oficialmente há um século, mas subcons-cientemente aproveitável.

São os filhos das operárias das unidades de produção high-tech que precisam de uma educação em Ciências que os permita não se submeterem como suas mães aos ditados da tecnologia do mercado. Se esta proposta não é suficiente para mudar o mundo, ela certamente é um início de con- 
tribuição à libertação. É uma práxis, "uma atividade didática com vista a um resultado" (Le Petit Robert) para professores.

É pensando na práxis, uma atividade com meta, que oferecerei uma série de oficinas participativas de ciências e matemática durante o $3^{\circ} \mathrm{Sim}$ pósio do ICASE. Por se tratar de atividades necessariamente práticas, concretas, seria uma contradição descrevê-las pormenorizadamente no papel aqui. Venham vivê-las comigo!

\section{RESUMO}

Foi-me solicitado um artigo "com a intenção de divulgar as idéias da cultura científica e tecnológica" como "atividade preparatória ao $3^{\circ}$ Simpósio do ICASE". Esta colocação me leva a tentar esclarecer o que seria aquela "cultura científica e tecnológica" e porque seria necessário divulgar suas idéias? Enquanto, você, leitor, me lê como "atividade preparatória" ao Simpósio, eu ando procurando fitas de papel, garrafas de plástico transparente, bexigas, pilhas usadas, plaquinhas de cobre, outras de zinco ou alumínio, conta-gotas, e flechas originais dos índios Kaingang. Com aquele material "tecnológico", e sem palestrar, oferecerei durante a nossa reunião algumas oficinas: acompanharei um grupo de duas dúzias de colegas-professores em seus esforços de fazer Ciência e matemática, envolvendo-se comigo em questionar o mundo material e técnico que nos rodeia, e de elucidar os conceitos matemáticos e físicos que nossas manipulações revelarão. Essas atividades terão como meta poder levar as crianças a viverem na sala de aula sessões de descobrimento e discussão tão ricas, surpreendentes e agradáveis como as que viveremos juntos entre docentes. Assim, possivelmente, ofereceremos alguma coisa de Ciência à nossa cultura.

\section{REFERÊNCIAS BIBLIOGRÁFICAS}

LORENZ, Edward, meteorologista; palestra durante a reunião anual da American Association for the Advancement of Science (AAAS); "Predictability: Does the Flap of a Butterflys Wings in Brazil Set off a Tornado in Texas?" (1972) 


\section{LEITURAS RECOMENDADAS}

ANDERSON, Sam; BAZIN, Maurice. Ciência e (In)Dependência, Lisboa: Livros Horizonte, 1977.

BAZIN, Maurice. Patterns across Cultures, Exploratorium (1998).

CIÊNCIA Hoje das crianças, Av. Venceslau Brás 71, fundos, 22290-140, Rio de Janeiro.

FREIRE, Paulo. Pedagogia do oprimido, Rio de Janeiro: Paz e Terra, 1970.

HOBSBAWM, Eric. The age of extremes, New York: Vintage Books, 1996.

LÉVY-LEBLOND, Jean-Marc. La Pierre de Touche, Paris: Éditions Gallimard, 1996.

MATH across Cultures, Exploratorium (1995,1997).

SCIENCE across Cultures, Exploratorium (1997). 